\title{
Síndrome de Rowell e lúpus eritematoso sistêmico: um diferencia( ${ }^{*}$
}

\section{Rowell's syndrome and systemic lupus erythematosus: a differential diagnosis}

\author{
Maira Mukai ${ }^{(1)}$, Michelle Tokarski ${ }^{(2)}$, Marilia B. Silva ${ }^{(3)}$, Thelma L. Skare ${ }^{(3)}$
}

\section{RESUMO}

A síndrome de Rowell é descrita como associação entre lúpus (discóide ou sistêmico) e eritema multiforme. Por apresentar lesões bolhosas, implica em diagnóstico diferencial das lesões bolhosas do próprio lúpus e de outras patologias bolhosas que podem se superimpor. Os autores descrevem um caso de síndrome de Rowell e revêem alguns aspectos desta entidade clínica.

Palavras-chave: lúpus eritematoso discóide, lúpus eritematoso sistêmico, síndrome de Rowell, eritema multiforme.

\section{INTRODUÇÃO}

As lesões cutâneas do lúpus eritematoso sistêmico (LES) estão entre as manifestações clínicas mais comuns desta doença e freqüentemente aparecem em seu quadro inicial $^{(1)}$. Entretanto, algumas formas de manifestação cutânea do LES são relativamente raras como, por exemplo, as erupções bolhosas, que representam menos de $5 \%$ do total ${ }^{(2)}$. Desta forma, toda vez que um paciente lúpico apresentar lesões bolhosas, o médico atendente deve proceder um cuidadoso diagnóstico diferencial entre as lesões cutâneas próprias do LES e as de uma outra doença bolhosa sobreposta. Entre estas últimas se incluem a dermatite herpetiforme, o penfigóide bolhoso, o pênfigo vulgar e o foliáceo, a epidermólise bolhosa acquisita, a doença por depósito linear de IgA, o eritema multiforme etc ${ }^{(3)}$.

\begin{abstract}
Rowell's syndrome is described as an association between (systemic or cutaneous) lupus erythematosus and erythema multiforme. The presence of bullous lesions indicates the necessity of a careful diagnosis in order to discriminate Rowell's syndrome from bullous lesions of lupus or from an association with other bullous diseases. The authors describe a case of Rowell's syndrome and review some aspects of this clinical entity.
\end{abstract}

Keywords: discoid lupus, systemic lupus erythematosus, Rowell's syndrome, erythema multiforme.

Uma forma rara de lesão bolhosa em pacientes com lúpus é a chamada síndrome de Rowell ${ }^{(4-9)}$ : associação de lúpus com eritema multiforme em pacientes portadores de anticorpos anti-Ro/SS-A e fator reumatóide (FR). Esta síndrome foi descrita inicialmente por Scholtz em1922 ${ }^{(10)}$ e, mais tarde, em 1963, por Rowell et al., sendo estes últimos autores os responsáveis pela descrição dos seus achaos laboratoriais $^{(8)}$

\section{RELATO DE CASO}

Trata-se de uma paciente do sexo feminino, 27 anos, com diagnóstico de lúpus eritematoso feito há cinco anos, em outro serviço, baseado na presença de fotossensibilidade, leucopenia, FAN positivo, artrite e rash malar. Há aproximadamente um ano experimentava surtos recorrentes de

\footnotetext{
* Hospital Universitário Evangélico de Curitiba (HUEC). Curso de Medicina da Faculdade Evangélica do PR (FEPAR). Recebido em 17/5/2002. Aprovado, após revisão, em 5/1/2003.

1. R2 Clínica Médica do Hospital Universitário Evangélico de Curitiba (HUEC).

2. R2 de Dermatologia do HUEC.

3. Profa. Assistente da Disciplina de Reumatologia do Curso de Medicina da FEPAR.
}

Endereşo para correspondência: Thelma L. Skare. R. João Alencar Guimarães, 796, CEP 80.310-420, Curitiba, PR, e-mail: tskare@onda.com.br 
lesões bolhosas disseminadas. Não notou qualquer associação entre o início destas lesões e o uso concomitante de medicamentos ou quadros infecciosos. Há cerca de seis meses iniciou o uso de cloroquina, sem notar melhora. Ao procurar o Serviço de Reumatologia do Hospital Universitário Evangélico de Curitiba, persistiu no uso de cloroquina, utilizando também prednisona $(10 \mathrm{mg} /$ dia $) . \mathrm{Na}$ ocasião apresentou queixas de lesões cutâneas em troncos e braços, cujo último surto iniciou-se há dois meses.

Ao exame físico apresentou lesões anulares e policíclicas associadas com vesículas periféricas na região do tronco e dos braços. Na palma das mãos observou-se lesões em alvo (Figuras 1 e 2).

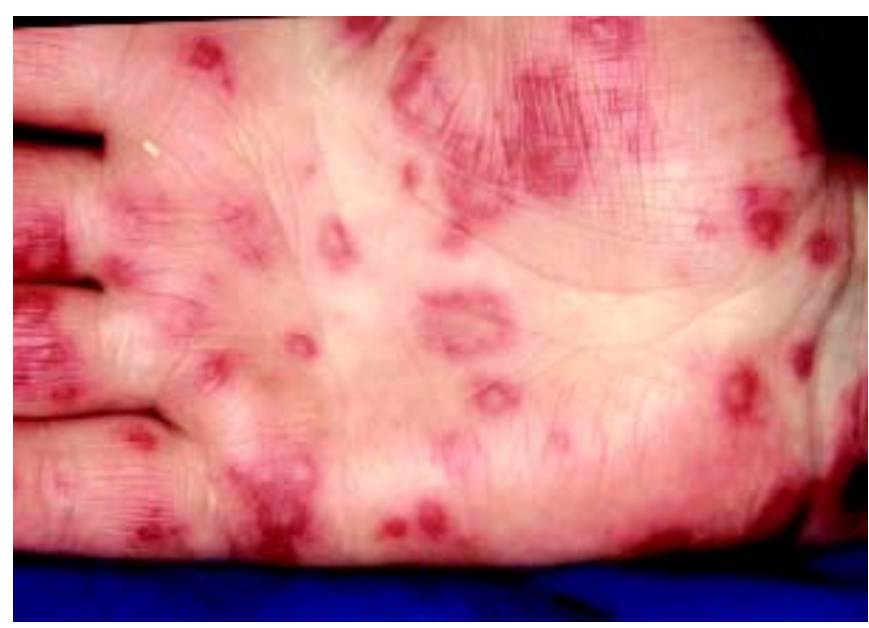

Figura 1 - Palma da mão mostrando lesões em alvo.

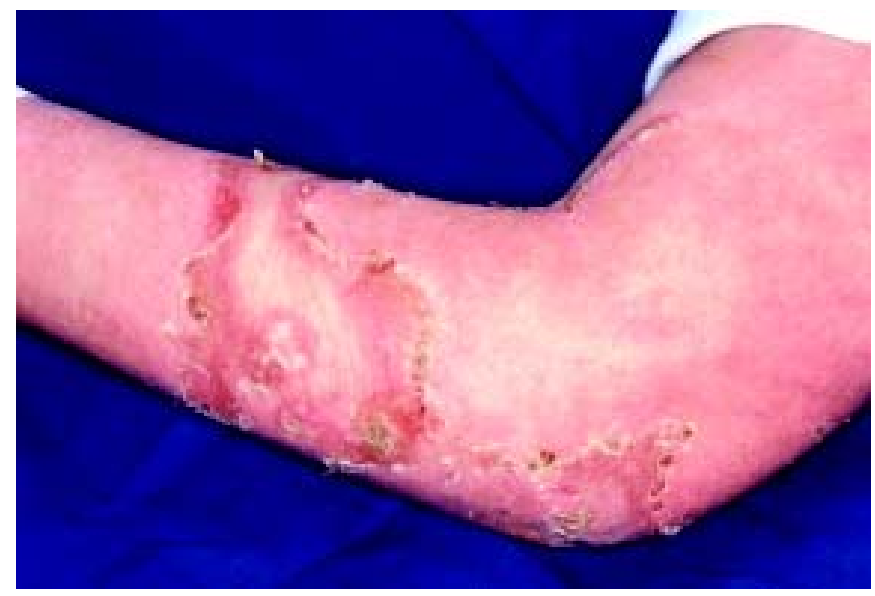

Figura 2 - Braço da paciente mostrando lesões bolhosas rotas.

A biópsia cutânea mostrou bolhas subepidérmicas, queratinócitos necróticos e infiltração inflamatória linfocítica perivascular na derme, compatível com eritema multiforme (Figura 3).

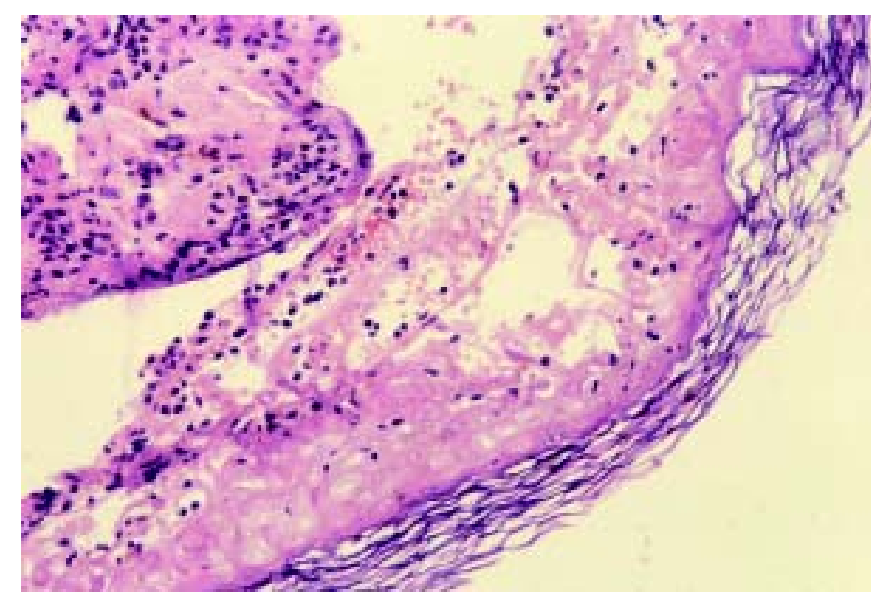

Figura 3 - Biópsia de pele de antebraço mostrando lesão bolhosa subepidérmica.

Hemograma mostrou um volume globular de 37,4\%, leucócitos de $6.600 / \mathrm{mm}^{3}$ com $70 \%$ de neutrófilos, 4 bastões, $20 \%$ de linfócitos e $1 \%$ de monócitos. As plaquetas foram de $278.000 / \mathrm{mm}^{3}$. Função hepática e renal foram normais. O FAN foi positivo, padrão pontilhado, no título de 1/640; anti-Ro=108,9U/ml $(\mathrm{N}<8,0 \mathrm{U} / \mathrm{ml})$; anti$\mathrm{La}=114,9 \mathrm{U} / \mathrm{ml}(\mathrm{N}<8,0 \mathrm{U} / \mathrm{ml})$; fator reumatóide, antiRNP, anti-Sm e anti-DNA foram negativos. A fração C3 do complemento foi de $97 \mathrm{mg} / \mathrm{dl}(\mathrm{N}=82$ a $201 \mathrm{mg} / \mathrm{dl})$ e a $\mathrm{C} 4$ foi de $15 \mathrm{mg} / \mathrm{dl}(\mathrm{N}=16$ a $50 \mathrm{mg} / \mathrm{dl})$.

$\mathrm{O}$ uso da cloroquina foi suspenso e a paciente foi tratada com corticóide na dose de $1 \mathrm{mg}$ de prednisona $/ \mathrm{kg} / \mathrm{dia}$. A resposta ao tratamento foi rápida e, após um mês, iniciouse uma diminuição gradual da dose.

Cerca de quatro meses depois, quando a paciente usava $30 \mathrm{mg}$ de prednisona/dia, as lesões cutâneas bolhosas recorreram de maneira extensa e a paciente necessitou de novo internamento. Reinstalou-se corticóide em doses altas com rápida regressão do processo. Associou-se, então, azatioprina, e o corticóide pôde ser gradualmente retirado.

Por dois anos, desde a última recidiva, a paciente foi acompanhada ambulatorialmente, e encontra-se exclusivamente em uso de azatioprina, sem retorno dos sintomas cutâneos e sem atividade clínica do lúpus. As lesões cutâneas curaram sem deixar cicatriz.

\section{DISCUSSÃO}

As lesões cutâneas típicas da síndrome de Rowell são compatíveis com as do eritema multiforme, o qual tende a poupar áreas de mucosa ${ }^{(6)}$. Têm sido descritas em pacientes com lúpus discóide ${ }^{(6,9)}$ ou sistêmico ${ }^{(4,7,9)}$ e estão associadas com a 
presença do FAN padrão salpicado e testes positivos para o FR e o anticorpo anti-Sj-T ${ }^{(6,8)}$. Este último anticorpo é identificado, atualmente, como sendo o próprio anticorpo antiRo/SS-A ${ }^{(11)}$. A presença do FR não tem sido uma constante nos casos descritos ${ }^{(4,12)}$ e o seu achado pode ser explicado pelo fato de que o antígeno Ro e agregados de $\operatorname{IgG}$ partilham epítopes comuns reagindo de maneira cruzada ${ }^{(11)}$.

$\mathrm{Na}$ análise da literatura sobre esta síndrome, verifica-se a preocupação com o fato de que estes casos possam representar apenas uma coincidência de patologias, ao invés de uma associação verdadeira ${ }^{(13)}$. Há, também, quem a considere uma forma de lúpus cutâneo subagudo ${ }^{(14)}$, apesar de existirem diferenças histológicas entre estas duas situações ${ }^{(8)}$. Uma terceira preocupação é a relativa à separação entre a síndrome de Rowell e as lesões bolhosas do próprio LES. $\mathrm{Na}$ Tabela 1 encontram-se alguns dos elementos que podem ser considerados para que esta diferenciação possa ser estabelecida.

Diante de um paciente lúpico com lesões bolhosas torna-se necessário proceder ao diagnóstico diferencial com relação a outras doenças bolhosas que podem aparecer de maneira independente. A Tabela 2 mostra as características clínicas das principais representantes deste grupo.

No caso descrito, houve possibilidade de que a cloroquina, além de não estar sendo efetiva, pudesse implicar no aparecimento das lesões bolhosas. Eritema multiforme e penfigóide bolhoso têm sido descritos com o uso deste
TABELA 1

DiagNÓSTICODIFERENCIAL DAS LESÕES CUTÂNEAS BOLHOSAS DO LES E DA SÍNDROME DE ROWELL ${ }^{(8)}$

\begin{tabular}{|c|c|c|}
\hline & Lúpus com lesões bolhosas & Sindrome de Rowell \\
\hline Distribuição & Em áreas expostas ao sol & $\begin{array}{l}\text { Afeta prim ariamente } \\
\text { os braços e as pernas; } \\
\text { mais raram ente } 0 \\
\text { tronco e a face }\end{array}$ \\
\hline \multirow[t]{2}{*}{ Histologia } & $\begin{array}{l}\text { Vesículas subepidérmicas } \\
\text { com neutrófilos, fragmentos } \\
\text { de núcleo e fibrina no topo } \\
\text { das papilas dérmicas }\end{array}$ & $\begin{array}{l}\text { Fase precoce: edema } \\
\text { de células endoteliais, } \\
\text { infiltrado mononuclear } \\
\text { perivascular }\end{array}$ \\
\hline & & $\begin{array}{l}\text { Fase tardia: degenera- } \\
\text { ção hidrópica, necrose } \\
\text { de queratinócitos, bo- } \\
\text { lhas subepidérmicas }\end{array}$ \\
\hline Curso & $\begin{array}{l}\text { Surtos de erupções cutâneas } \\
\text { de acordo com a ativi dade do } \\
\text { LES. Boa resposta a dapsona }\end{array}$ & $\begin{array}{l}\text { Duração prolongada; a } \\
\text { recidiva é comum }\end{array}$ \\
\hline
\end{tabular}

medicamento ${ }^{(16,17)}$. Entretanto, a recorrência de um novo surto de lesões após a retirada desta droga tornou esta possibilidade improvável.

Um segundo aspecto peculiar a este caso, foi o de que as lesões cutâneas exigiram uso prolongado de altas doses de corticóide, sendo necessária a administração de azatioprina como poupador deste medicamento.

TABELA 2

CARACTERÍSTICAS DE OUTRAS DOENÇAS QUE CURSAM COM ERUPÇÕES BOLHOSAS ${ }^{(13,14)}$

\begin{tabular}{|c|c|c|c|}
\hline Nome & Epidemiologia & Características clínicas & Observações \\
\hline Pênfigo vulgar & $\begin{array}{l}\text { Raro; início em meia idade; mais } \\
\text { comum em descendente de judeus e } \\
\text { moradores da região mediterrânea }\end{array}$ & $\begin{array}{l}\text { Bolhas flácidas e erosões; lesões } \\
\text { dolorosas que se iniciam pela boca }\end{array}$ & $\begin{array}{l}\text { Pode associar-se a timomas e miastenia } \\
\text { gravis }\end{array}$ \\
\hline Pênfigo foliáceo & Mei a-idade & $\begin{array}{l}\text { Lesões crostosas na face, costas e } \\
\text { e anterior do peito }\end{array}$ & \\
\hline Penfigóide bolhoso & Idosos & $\begin{array}{l}\text { Bolhas tensas e placas de urticária } \\
\text { em superficies flexoras }\end{array}$ & \\
\hline $\begin{array}{l}\text { Dermatite } \\
\text { herpetiform e }\end{array}$ & $\begin{array}{l}\text { Mais em m ulheres com idade en tre } \\
20 \text { e } 40 \text { anos }\end{array}$ & $\begin{array}{l}\text { Escoriações ou bolhas simétricas } \\
\text { nas superfícies extensoras de co- } \\
\text { tovelos, joelhos, sacro e nádegas. } \\
\text { Prurido in tenso }\end{array}$ & $\begin{array}{l}\text { Pode estar associada com enteropatia } \\
\text { sensivel ao glúten }\end{array}$ \\
\hline $\begin{array}{l}\text { Epidermólise } \\
\text { bolhosa acquisita }\end{array}$ & Mei a-idade & $\begin{array}{l}\text { Bolhas tensas em pele sem infla- } \\
\text { mação; mais em ár eas sujeitas a } \\
\text { trauma (cotovelos, joelhos e dorso } \\
\text { das mãos). Cura com cicatriz }\end{array}$ & $\begin{array}{l}\text { Associada com lesões de mucosa, oral } \\
\text { e ocular e pode cursar com } \\
\text { alopecia cicatricial }\end{array}$ \\
\hline $\begin{array}{l}\text { Dermatose bolhosa } \\
\text { por depósito de IgA }\end{array}$ & Início após a puberdade & $\begin{array}{l}\text { Bolhas semelhantes às do penfigóide } \\
\text { bolhoso ou dermatite herpetiforme, } \\
\text { porém men os simétricas }\end{array}$ & $\begin{array}{l}\text { Pode estar associada com câncer } \\
\text { (prin cipalmen te linfo mas) }\end{array}$ \\
\hline
\end{tabular}




\section{REFERÊNCIAS}

1. Dubois EL, Wallace DJ: Clinical and laboratory manifestation of systemic lupus erythematosus. In: Dubois EL, Wallace DJ (Eds). Lupus erythematosus. $3^{\text {rd }}$ ed, 317-449. Lea \& Febiger. Philadelphia, 1987.

2. Shirahama S, Furukawa F, Yagi H, et al: Bullous systemic lupus erythematosus: detection of antibodies against noncollagenous domain of type VII collagen. J Am Acad Dermatol 38(5): 844-8, 1998.

3. Parker F: Skin Diseases. In: Wyngaarden JB, Smith LH, Bennet JC (Eds). Cecil Textbook of Medicine, $19^{\text {th }} \mathrm{ed}$, WB Saunders, Philadelphia, 2280-6, 1992.

4. Heyl T, Meyer T: Lupus erythematosus with erythema multiforme (Rowell's syndrome). S Afr Med J 65:568-9, 1984.

5. Crickx B, Crickx L, Vissuzaine C, Grossin M, Belaich S: Lupus ërythémateux chronique avec lésions a type d'erythéme polymorphe (Syndrome de Rowell). Ann Dermatol Venereol 112:705-6, 1985.

6. Parodi A, Drago EF, Varaldo G, Rebora A: Rowell's syndrome: report of a case. J Am Acad Dermatol 21:374-7, 1989.

7. Fiallo P, Tagliapietra A-G, Santoro G, Venturino E: Rowell's syndrome. Int J Dermatol 34(9):635-6, 1995.

8. Fitzgerald EA, Fitzgerald DO, Purcell SM, Kantor GR, Goldman HM: Rowell's syndrome: report of a case. J Am Acad Dermatol 35(5):801-3, 1996.
9. Lawrence CM, Marshall TL, Byrne JPH: Lupus erythematosus associated with erythema, multiforme-like lesions in identical twins. BrJ Dermatol 107:349-56, 1982.

10. Scholtz M: Lupus erythematosus acutus disseminatus haemorragicus. Arch Dermatol Syph 6:466, 1922.

11. Provost TT, Watson R, Simmons-O'Brien E: Significance of the anti-Ro (SS-A) antibody in evaluation of patients with cutaneous manifestations of a connective tissue disease. J Am Acad Dermatol 35(2):147-69, 1996.

12. Sanchez M, Cruces J, Fonseca A, Taboada M, Cacharron J, Peteiro C: Lupus eritematoso sistémico com manifestaciones cutáneas de eritema multiforme. Actas dermo-sifilograficas: 631-8, 1975.

13. Shteyangarts AR, Warner MR, Camisa C: Lupus erythematosus associated with erythema multiforme: Does Rowell's syndrome exist? J Am Acad Dermatol 40(5):773-7, 1999.

14. Bickle KM, Roark TR, Hsu S: Autoimmune bullous dermatoses: A review Am. Fam Physician 65(9):1861-70, 2002.

15. Cotell S, Robinson ND, Lawrence S, Chan LS: Autoimmune blistering skin diseases Am J Emerg Med 18(3):288-99, 2000.

16. Millard TP, Smith HR, Black MM, Barker JNWN: Bullous pemphigoid developing during systemic therapy with chloroquine. Clin Exp Dermatol 24:263-5, 1999.

17. Ortel B, Sivayathorn A, Hönigsmann H: An unusual combination of phototoxicity and Stevens-Johnson syndrome due to antimalarial therapy. Dermatologica 178:39-42, 1989. 